American Journal of Applied Sciences 7 (8): 1168-1173, 2010

ISSN 1546-9239

(C) 2010 Science Publications

\title{
Voltage Oriented Control Applied to a Grid Connected Photovoltaic System with Maximum Power Point Tracking Technique
}

\author{
Rym Marouani and Abdelkader Mami \\ Laboratory of Analyse and Control of Systems, Department of Electric Engineering, \\ National School of Engineering of Tunis, PG. 37, Le Belvedere 1002, Tunis, Tunisia
}

\begin{abstract}
Problem statement: This study presented a grid connected photovoltaic system with voltage oriented control. This system contains the problem of degradation of photovoltaic power with climatic factors and the problem of synchronization of currents to be injected to the grid. Approach: In order to optimize the photovoltaic energy generation, we developed a new maximum power point tracking algorithm and we use a phase locked loop to solve the problem of synchronization of grid voltage and current. Results: The model of the grid connected photovoltaic system had been implemented in the MATLAB/SIMULINK software and simulation studies have been presented. Conclusion: Results had proved the effectiveness of the proposed system, the utility of the maximum power point tracker and the robustness of the phase locked loop.
\end{abstract}

Key words: Grid connected photovoltaic system, voltage oriented control, maximum power point tracking, phase locked loop

\section{INTRODUCTION}

The installation of renewable energy power generation has been one of the new trends in power electronic technology.

Among various renewable energy types, photovoltaic power generation systems are expected to play an important role as a clean electricity power source in meeting future electricity demands.

One of the most important applications is the Grid Connected Photovoltaic System GCPS whose makes the object of this study, where its typical structure is composed by a photovoltaic generator PVG, a DC-bus, a PWM inverter and a grid utility.

However, the photovoltaic grid application presents the problem of achieving the maximum power point tracking aiming at maximizing the extracted energy irrespective of the irradiation conditions.

In this study, we present a new maximum power point tracking algorithm which calculates the reference DC voltage versus the solar illumination in order to force the photovoltaic generator to operate at its maximum power point.

In our case, efficient simulation before practical control implantation is required. This study investigates the utilization of the MATLAB/SIMULINK software whose enables an efficient control development based on specific system libraries or toolboxes.

\section{MATERIALS AND METHODS}

Modeling of the grid connected photovoltaic system: The configuration of the GCPS presented in this study can be described by Fig. 1. The system consists of a PVG, a DC-bus, an inverter, a grid filter and a grid utility, as cited in (Kim, 2007; Kim et al., 2009).

Modeling of the PVG: The I-V characteristic of the PVG is represented by (1), as in (Marouani and Bacha, 2009).

$\mathrm{I}_{\mathrm{p}}=\mathrm{I}_{\mathrm{ph}}-\mathrm{I}_{\mathrm{ss}}\left[\exp \left(\mathrm{V}_{\mathrm{p}} / \mathrm{V}_{\mathrm{T}}\right)-1\right]$

With:

$I_{p}$ and $V_{p}=$ The PV current and voltage respectively

$\mathrm{I}_{\mathrm{ph}} \quad=$ The light-generated current

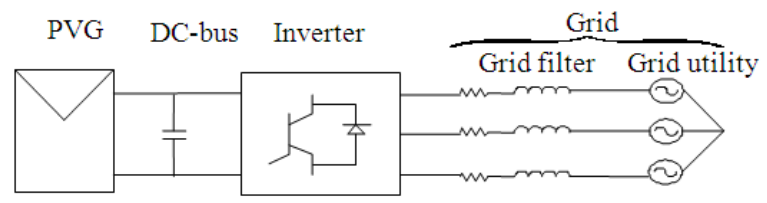

Fig. 1: Typical configuration of a grid connected photovoltaic system

Corresponding Author: Rym Marouani, Laboratory of Analyse and Control of Systems, Department of Electric Engineering, National School of Engineering of Tunis, PG. 37, Le Belvedere 1002, Tunis, Tunisia Tel: 21697693722 


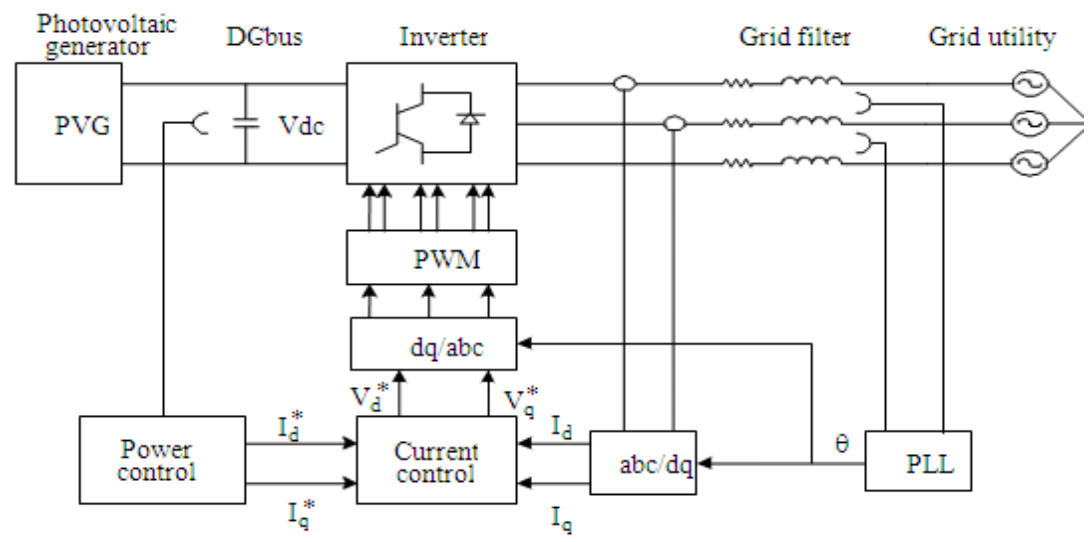

Fig. 2: The entire schematic of the studied grid connected photovoltaic system with the voltage oriented control

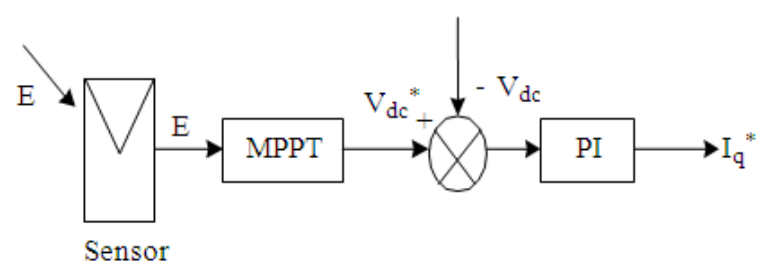

Fig. 3: The real power control

$\mathrm{I}_{\mathrm{ss}} \quad=$ The reverse saturation current

$\mathrm{V}_{\mathrm{T}}=\mathrm{n} \cdot \mathrm{K}_{\mathrm{B}} \cdot \mathrm{T} / \mathrm{q}=$ The thermodynamic potential

$\mathrm{n} \quad=$ The ideality factor of the PN junction

$\mathrm{K}_{\mathrm{B}} \quad=$ The Boltzman's constant $\left(1.38 \times 10^{-23}\right.$ $\mathrm{J} / \mathrm{K})$

$\mathrm{T} \quad=$ The temperature of a photovoltaic array $(\mathrm{K})$

q

$=$ The electron charge $\left(1.6 \times 10^{-19} \mathrm{C}\right)$

Modeling of the DC bus: The DC bus current $I_{c}$ is given by (2), as in (Marouani and Bacha, 2009):

$\mathrm{I}_{\mathrm{c}}=\mathrm{CdV}_{\mathrm{pv}} / \mathrm{dt}$

Modeling of the inverter: The grid connection inverter consists on a three-phase voltage source inverter with three independent arms. Each one includes two switches which are complementary and controlled by the Pulse Width Modulation PWM, as in (Lee et al., 2008; Weslati et al., 2008; Yu et al., 2006).

The inverter's voltages $\left(\mathrm{V}_{\mathrm{a}}, \mathrm{V}_{\mathrm{b}}, \mathrm{V}_{\mathrm{c}}\right)$ are expressed in terms of the upper switches as follows:

$$
\left[\begin{array}{c}
\mathrm{V}_{\mathrm{a}} \\
\mathrm{V}_{\mathrm{b}} \\
\mathrm{V}_{\mathrm{c}}
\end{array}\right]=\frac{\mathrm{V}_{\mathrm{p}}}{3}\left[\begin{array}{ccc}
2 & -1 & -1 \\
-1 & 2 & -1 \\
-1 & -1 & 2
\end{array}\right]\left[\begin{array}{l}
\mathrm{K}_{1} \\
\mathrm{~K}_{2} \\
\mathrm{~K}_{3}
\end{array}\right]
$$

$\mathrm{K}_{1}, \mathrm{~K}_{2}$ and $\mathrm{K}_{3}$ are the controller signals applied to the switches.

The inverter's current $I_{\text {inv }}$ is given by (4):

$\mathrm{I}_{\mathrm{inv}}=\mathrm{K}_{1} \mathrm{I}_{\mathrm{a}}+\mathrm{K}_{2} \mathrm{I}_{\mathrm{b}}+\mathrm{K}_{3} \mathrm{I}_{\mathrm{c}}$

where, $\left(I_{a}, I_{b}, I_{c}\right)$ are the currents to be injected to the grid.

Modelling of the grid utility: Considering the grid voltages $\left(\mathrm{E}_{\mathrm{d}}, \mathrm{E}_{\mathrm{q}}\right)$ as control inputs, the grid filter currents $\left(I_{d}, I_{q}\right)$ as state variables, the electrical model of the grid in the d-q referential axis is given by (5), as in (Weslati et al., 2008):

$$
\left\{\begin{array}{l}
\frac{d I_{d}}{d t}=-\frac{R}{L} I_{d}+\omega I_{q}+\frac{K_{d}}{L} V_{p}-\frac{1}{L} E_{d} \\
\frac{d I_{q}}{d t}=-\omega I_{d}-\frac{R}{L} I_{q}+\frac{K_{q}}{L} V_{p}-\frac{1}{L} E_{q}
\end{array}\right.
$$

Where:

$\mathrm{R}$ and $\mathrm{L}=$ The resistance and the inductance of the grid filter respectively

$\omega=$ The angular frequency of the grid

$\mathrm{K}_{\mathrm{d}}$ and $\mathrm{K}_{\mathrm{q}}=$ The controller signals of the inverter

Voltage oriented control: The entire schematic of the Grid Connected Photovoltaic System GCPS with the Voltage Oriented Control VOC is described by Fig. 2 and detailed in (Kim et al., 2009; Ostrem et al., 2006).

The power control: This subsystem controls the real and reactive power of the inverter, (Kim et al., 2009):

- The real power is controlled by the $q$-axis current $I_{q}$ as shown in Fig. 3. A maximum power point 
tracking algorithm MPPT to be addressed later, generates the reference value of the DC-bus voltage $\mathrm{V}_{\mathrm{dc}}{ }^{*}$ to be compared to the actual value $\mathrm{V}_{\mathrm{dc}}$

- The error between $\mathrm{V}_{\mathrm{dc}}{ }^{*}$ and $\mathrm{V}_{\mathrm{dc}}$ is processed as $\mathrm{I}_{\mathrm{q}}{ }^{*}$ through a proportional-integral PI controller

- The reactive power is controlled by the d-axis current $I_{d}$ as shown in Fig. 4. For a unity power factor, the desired value of the reactive power $\mathrm{Q}_{\mathrm{inv}}{ }^{*}$ is compared to the reactive power $\mathrm{Q}_{\text {inv }}$. The error between $\mathrm{Q}_{\text {inv }}{ }^{*}$ and $\mathrm{Q}_{\text {inv }}$ is processed as $\mathrm{I}_{\mathrm{d}}{ }^{*}$ through a PI controller

The maximum power point tracking technique: The PVG operates at a certain voltage which corresponds to the maximum power point under different climatic conditions, i.e., the solar illumination E. In our case, the MPPT generates the reference DC-bus voltage versus the solar illumination given by Table 1 . This method has been detailed in (Marouani and Bacha, 2009; Tarik Duru, 2006).

Using the curve fitting technique, the MPPT can be a polynomial function of $\mathrm{V}_{\mathrm{dc}}{ }^{*}$ versus $\mathrm{E}$ given by (6):

$$
\begin{aligned}
\mathrm{V}_{\mathrm{dc}}^{*}= & -3.4393+0.1328 \mathrm{E}+2.2352 .10^{-4} \mathrm{E}^{2} \\
& -1.5460 .10^{-7} \mathrm{E}^{3}+4.2288 .10^{-11} \mathrm{E}^{4}
\end{aligned}
$$

The current control: The AC-side circuit equations in the synchronously rotating $\mathrm{d}-\mathrm{q}$ reference frame are given by (7), (Kim et al., 2009):

$$
\left\{\begin{array}{l}
\mathrm{V}_{\mathrm{d}}=\mathrm{E}_{\mathrm{d}}-\mathrm{LdI}_{\mathrm{d}} / \mathrm{dt}-\omega \mathrm{LI}_{\mathrm{q}} \\
\mathrm{V}_{\mathrm{q}}=\mathrm{E}_{\mathrm{q}}-\mathrm{LdI}_{\mathrm{q}} / \mathrm{dt}+\omega \mathrm{LI}_{\mathrm{d}}
\end{array}\right.
$$

Where:

$\mathrm{E}_{\mathrm{d}}$ and $\mathrm{E}_{\mathrm{q}}=$ The $\mathrm{d}$ - and $\mathrm{q}$-axis components of the grid side voltage respectively

$\mathrm{V}_{\mathrm{d}}$ and $\mathrm{V}_{\mathrm{q}}=$ Those of the inverter voltage

$\omega=$ The system angular frequency

To provide direct use of the sensed currents which present intrinsic error, (7) may be transformed to (8) using PI controllers:

$$
\left\{\begin{array}{l}
\mathrm{V}_{\mathrm{d}}=\mathrm{E}_{\mathrm{d}}-\omega \mathrm{LI}_{\mathrm{q}}-\mu_{\mathrm{d}} \\
\mathrm{V}_{\mathrm{q}}=\mathrm{E}_{\mathrm{q}}+\omega \mathrm{LI}_{\mathrm{d}}-\mu_{\mathrm{q}}
\end{array}\right.
$$

Where:

$$
\left\{\begin{array}{l}
\mu_{\mathrm{d}}=\left(\mathrm{K}_{\mathrm{p}}+\mathrm{K}_{\mathrm{i}} / \mathrm{s}\right)\left(\mathrm{I}_{\mathrm{d}}^{*}-\mathrm{I}_{\mathrm{d}}\right) \\
\mu_{\mathrm{q}}=\left(\mathrm{K}_{\mathrm{p}}+\mathrm{K}_{\mathrm{i}} / \mathrm{s}\right)\left(\mathrm{I}_{\mathrm{q}}^{*}-\mathrm{I}_{\mathrm{q}}\right)
\end{array}\right.
$$

where, $\mathrm{K}_{\mathrm{p}}$ and $\mathrm{K}_{\mathrm{i}}$ are the proportional and integral gains of the PI controllers.

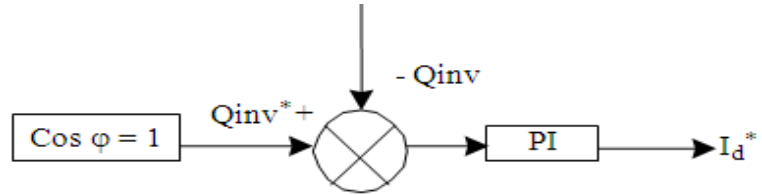

Fig. 4: The reactive power control

Table 1: Reference DC-bus voltage versus the illumination value

\begin{tabular}{ll}
\hline $\mathrm{E}\left(\mathrm{w} \mathrm{m}^{-2}\right)$ & $\mathrm{Vdc} *(\mathrm{~V})$ \\
\hline 100 & 162.6 \\
200 & 186.2 \\
300 & 203.0 \\
400 & 216.0 \\
500 & 226.5 \\
600 & 235.3 \\
700 & 242.8 \\
800 & 249.3 \\
900 & 255.0 \\
1000 & 260.0 \\
\hline
\end{tabular}

The current controller compares the reference and the actual values of the current and generates the desired value of the inverter voltage to be injected to the grid utility and which are given by (10):

$\left\{\begin{array}{l}\mathrm{V}_{\mathrm{d}}^{*}=\mathrm{V} \cos \delta \\ \mathrm{V}_{\mathrm{q}}^{*}=\mathrm{V} \sin \delta\end{array}\right.$

Where:

$$
\left\{\begin{array}{l}
\mathrm{V}=\sqrt{\mathrm{V}_{\mathrm{d}}^{2}+\mathrm{V}_{\mathrm{q}}^{2}} \\
\delta=\operatorname{tg}^{-1}\left(\mathrm{~V}_{\mathrm{d}} / \mathrm{V}_{\mathrm{q}}\right)
\end{array}\right.
$$

Where:

$\mathrm{V}_{\mathrm{d}}$ and $\mathrm{V}_{\mathrm{q}}=$ The active and reactive reference voltages respectively

$\mathrm{V}=$ The absolute value of the reference voltage

$\delta$

$=$ The reference angle correction given by the VOC system

Based on these equations, a current controller may be implemented as shown in Fig. 5.

The phase locked loop: The PLL used in this study is based on zero crossing voltage detection and the utilization of the quadrate of the input signals, as it is shown in Fig. 6, as in (Chayawatto et al., 2009; Chung, 2000; Han et al., 2009):

- $\mathrm{E}_{\mathrm{d}}{ }^{*}=0$ : The synchronization signals based on this technique has a simple structure. By keeping $\mathrm{E}_{\mathrm{d}}{ }^{*}=$ 0 , the synchronous reference voltage component $E_{d}$ is minimized and thereby the PLL will remain locked to the input voltages $\mathrm{E}_{\alpha}$ and $\mathrm{E}_{\beta}$ 


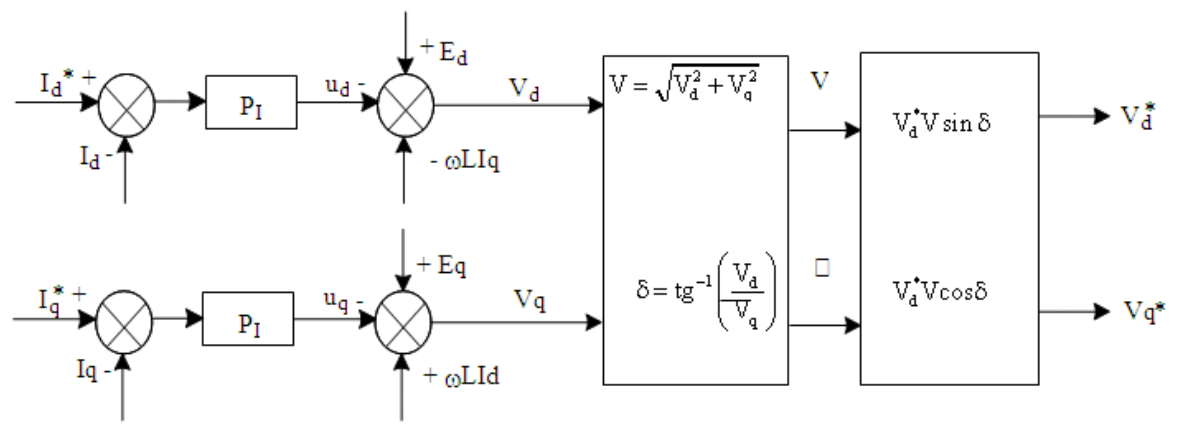

Fig. 5: The current controller

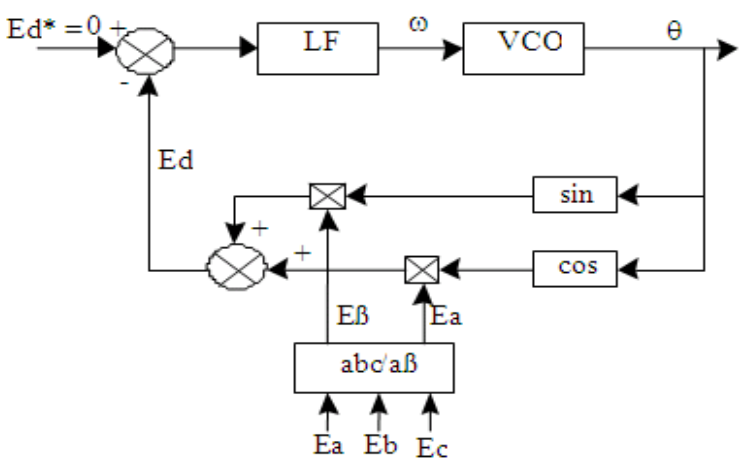

Fig. 6: The phase locked loop

- Using of the quadrate of the input signals: The input signals are multiplied with internal signals as in (12):

$$
\mathrm{E}_{\mathrm{d}}=\mathrm{E}_{\alpha} \sin \theta+\mathrm{E}_{\beta} \cos \theta
$$

The PLL generates a rotating reference angle $\theta$ synchronized to the voltage signals $\mathrm{E}_{\alpha}$ and $\mathrm{E}_{\beta}$.

When the grid voltage is restarted, the PLL will effectively synchronize and the system may be reconnected to the grid.

- The loop filter LF is a PI controller used in order to give a good trade-off between stability and dynamic performance. Its transfer function is given by (13):

$\mathrm{H}_{\mathrm{LF}}(\mathrm{s})=\mathrm{k}_{\mathrm{p}}+\mathrm{k}_{\mathrm{i}} / \tau_{\mathrm{i}} \mathrm{s}$

$\mathrm{k}_{\mathrm{p}}$ and $\mathrm{k}_{\mathrm{i}}$ are respectively the proportional and the integral gains of the PI controller.

- The Voltage Controlled Oscillator VCO is an integrator described by (14):
$\mathrm{H}_{\mathrm{vco}}(\mathrm{s})=1 / \mathrm{s}$

\section{RESULTS}

A complete Simulink-MATLAB simulation of the Grid Connected Photovoltaic System with the Voltage Oriented Control and the Maximum Power Point Tracking algorithm has been carried out with the following parameters:

- The PVG is composed of 4 series modules. Those modules are amorphous. Each one presents the following characteristics: Nominal peak power: 60 wp, Nominal voltage: $67 \mathrm{~V}$, Nominal current: 0.9 A, Open-circuit voltage: $92 \mathrm{~V}$ and Short-circuit current: 1.19 A

- The DC-bus capacitance: $\mathrm{C}=20010^{-3} \mathrm{~F}$

- The grid filter: $\mathrm{R}=5 \Omega, \mathrm{L}=0.02 \mathrm{H}$

- The grid voltage: $220 \mathrm{~V} / 50 \mathrm{~Hz}$

\section{DISCUSSION}

The simulation is based on the variation of the solar illumination E as shown in Fig. 7.

So, the reference DC voltage calculated by the MPPT and used by the VOC has the following waveform (Fig. 8).

Following this variation of the solar illumination, the current injected to the grid can be described by Fig. 9 and 10.

In the transient of change of $\mathrm{E}$, we can see the variation of the grid current in Fig. 10 and 11.

So, we can demonstrate the importance of the Maximum Power Point Tracking algorithm MPPT in resolution of the problem of the degradation of the climatic factors and the utility of the Voltage Oriented Control in the control of the GCPS. 


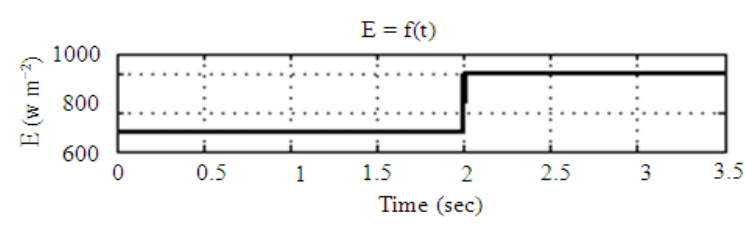

Fig. 7: The solar illumination waveform

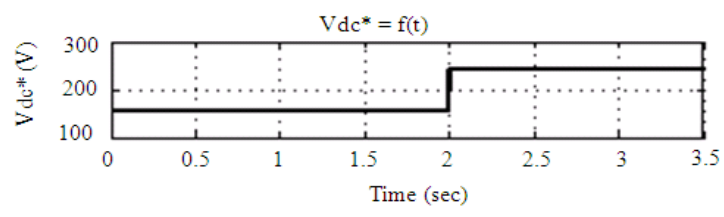

Fig. 8: The reference DC voltage waveform

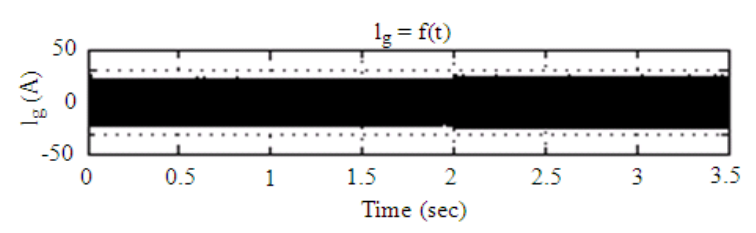

Fig. 9: The grid current waveform

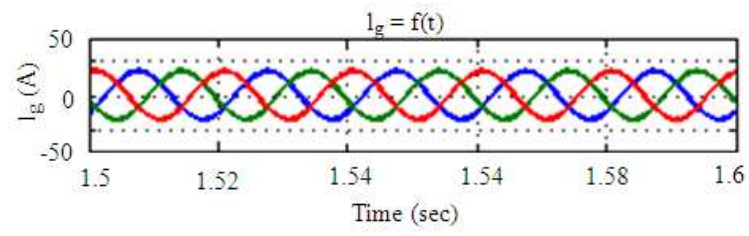

Fig. 10: Zoom of the grid current waveform

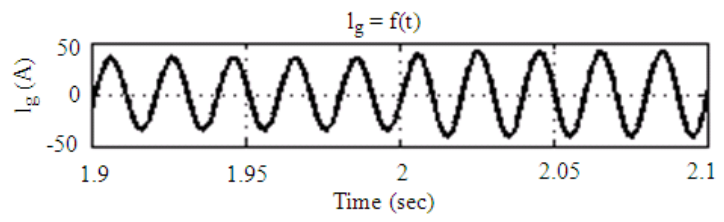

Fig. 11: Variation of the grid current at the transient of change of $\mathrm{E}$

We can see also the angle $\theta$ calculated by the Phase Locked Loop in Fig. 12.

We can see also the waveform of the grid voltage in Fig. 13.

We can prove here the robustness of the Phase Locked Loop PLL in the synchronization of the grid voltage.

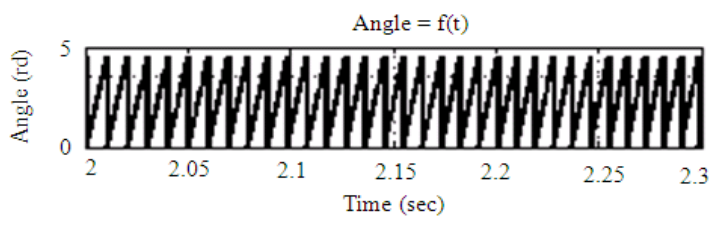

Fig. 12: The angle $\theta$ calculated by the PLL

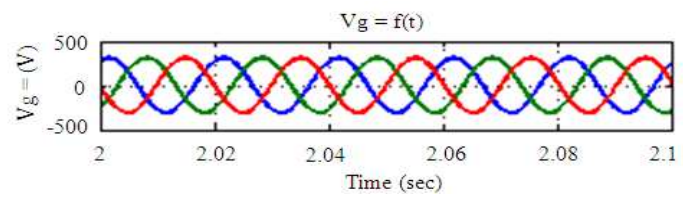

Fig. 13: The grid voltage waveform

\section{CONCLUSION}

This study is focused on the modelling and simulation of a grid connected photovoltaic system controlled by the voltage oriented control.

The MPPT has proved its utility in tracking of the maximum power point and the optimization of the photovoltaic power generation.

The phase locked loop used in this study has proved its robustness and effectiveness in synchronization of the grid voltage and current.

\section{REFERENCES}

Chayawatto, N., K. Kirtikara, V. Monyakul, C. Jivacate and D. Chenvidhya, 2009. DC-AC switching converter modeling of a PV grid-connected system under islanding phenomena. Renew. Energy, 34: 2536-2544. DOI: 10.1016/j.renene.2009.05.002

Chung, S.K., 2000. Phase-locked loop for gridconnected three-phase power conversion systems. IEE Proc.-Elect. Power Appli., 147: 213-219. DOI: 10.1049/ip-epa:20000328

Han, Y., L. Xu, M.M. Khan, G. Yao and L.D. Zhou et al., 2009. A novel synchronization scheme for gridconnected converters by using adaptative linear optimal filter based PLL (ALOF-PLL). Simulat. Model. Pract. Theory, 17: 1299-1345. DOI: 10.1016/j.simpat.2009.05.004

Kim, I.S., 2007. Robust maximum power point tracker using sliding mode controller for the three-phase grid-connected photovoltaic system. Solar Energy, 81: 405-414. DOI: 10.1016/j.solener.2006.04.005

Kim, S.K., J.H. Jeon, C.H. Cho, E.S. Kim and J.B. Ahn, 2009. Modeling and simulation of a grid-connected PV generation system for electromagnetic transient analysis. Solar Energy, 83: 664-678. DOI: 10.1016/j.solener.2008.10.020 
Lee, S.H., S.G. Song, S.J. Park, C.J. Moon and M.H. Lee, 2008. Grid-connected photovoltaic system using current-source inverter. Solar Energy, 82: 411-419. DOI: 10.1016/j.solener.2007.10.006

Marouani, R. and F. Bacha, 2009. A maximum-powerpoint tracking algorithm applied to a photovoltaic water-pumping system. Proceeding of the 8th International Symposium on Advanced Electromechanical Motion Systems and Electric Drives Joint Symposium, July. 1-3, IEEE Xplore Press, Lille, pp: 1-6. DOI: 10.1109/ELECTROMOTION.2009.5259078

Ostrem, T., W. Sulkowski, L.E. Norum and C. Wang, 2006. Grid connected Photovoltaic (PV) inverter with robust Phase-Locked Loop (PLL). Proceeding of the IEEE/PES Transmission and Distribution Conference and Exposition, Aug. 15-18, IEEE Xplore Press, Caracas, pp: 1-7. DOI: 10.1109/TDCLA.2006.311434
Tarik Duru, H., 2006. A maximum power tracking algorithm based on $I_{m p p}=f\left(P_{\max }\right)$ function for matching passive and active loads to a photovoltaic generator. Solar Energy, 80: 812-822. DOI: 10.1016/j.solener.2005.05.016

Weslati, Y., A. Sellami, F. Bacha and R. Andoulsi, 2008. Sliding mode control of a photovoltaic grid connected system. J. Elect. Syst., 4: 24-38. http://www.esrgroups.org/journal/jes/papers/4_3_6. pdf

Yu, B., Y. Jung, J. So, H. Hwang and G. Yu, 2006. A robust anti-islanding method for grid-connected photovoltaic inverter. Proceeding of the Conference Record of the 2006 IEEE 4th World Conference on Photovoltaic Energy Conversion, May 2006, IEEE Xplore Press, Waikoloa, HI., pp: 2242-2245. DOI: 10.1109/WCPEC.2006.279956 